Research Article

\title{
Study of the effect of post-operative medical management on peptic ulcer in patients of perforated peptic ulcer disease
}

\author{
Sudhir B. Deshmukh ${ }^{1}$, Koushal U. Kondawar ${ }^{2}$, Satish Gireboinwd ${ }^{3}$, Meghraj J. Chawada ${ }^{4}$
}

${ }^{1}$ Professor and HOD, ${ }^{2}$ PG Student, ${ }^{3}$ Assistant Professor, ${ }^{4}$ Associate Professor, Department of General Surgery, S. R. T. R. Government Medical College, Ambejogai, Maharashtra, India

Received: 11 May 2016

Accepted: 14 May 2016

*Correspondence:

Dr. Meghraj J. Chawada

E-mail: dr.meghrajchawada@gmail.com

Copyright: (C) the author(s), publisher and licensee Medip Academy. This is an open-access article distributed under the terms of the Creative Commons Attribution Non-Commercial License, which permits unrestricted non-commercial use, distribution, and reproduction in any medium, provided the original work is properly cited.

\begin{abstract}
Background: Peptic ulcer disease remains one of the most prevalent diseases of the gastrointestinal tract with annual incidence 1 ranging from $0.1 \%$ to $0.3 \%$ in India. Cases of peptic ulcer perforation are commonly encountered in our institute. The objective was to study the effect of post-operative medical management on peptic ulcer in patients of perforated peptic ulcer disease.

Methods: A prospective non randomized study was conducted among all diagnosed cases of peptic ulcer perforation patients admitted through emergency or OPD in surgery ward in our hospital. Patient's case record was evaluated to collect following data: personal information, past history of peptic ulcer disease, use of non-steroidal antiinflammatory drugs for heart disease or osteoarthritis was taken. Tests such as detail clinical history, patient's prescription, rapid urease test, upper GI endoscopy were done.

Results: Most common age group affected is, 50 years and above. Duodenal perforations were more common in age group of 50 years and above. Most of these patients present with clinical signs of peritonitis 24 hours after onset of pain. $84 \%$ of total patients were male patients and $16 \%$ were female patients. Among the patient of peptic ulcer perforation, duodenal perforation is more common, and which is most common cause of perforation peritonitis. Guarding and rigidity was present in $84 \%$ of patients. Diagnosis is made clinically and confirmed by presence of pneumoperitoneum on radiograph. Exploratory laparotomy with simple closure of perforation with omental patch after that peritoneal lavage with normal saline is commonest operative management perforated peptic ulcer. Most common post-operative complication observed was wound infection and lower respiratory tract infection. The overall mortality was $4 \%$.

Conclusions: Perforation peritonitis is common in elderly population. Pain in abdomen and distension of abdomen are most common presenting feature. Early diagnosis by clinical assessment and presence of pneumoperitoneum is important followed by resuscitation and laparotomy with simple closure of perforation.
\end{abstract}

Keywords: Peritonitis, Laparotomy, Resuscitation

\section{INTRODUCTION}

Peptic ulcer disease (PUD) remains one of the most prevalent diseases of the gastrointestinal tract with annual incidence 1 ranging from $0.1 \%$ to $0.3 \%$ in India. Cases of peptic ulcer perforation are commonly encountered in our institute. The high incidence of mortality and morbidity associated with this condition, promoted us to carry out an in depth study of this condition. There are well known two major precipitating factors: Helicobacter pylori infection and the use of non-steroidal anti-inflammatory drugs (NSAIDs) and the ulcer incidence increase with age for both duodenal and gastric ulcers. 
PUD is considered as mucosal functional derangements due to intra luminal aggressive factors and defects in endogenous defense mechanisms affecting the mucosa and extends through the muscularis mucosa. Some of these functional defects may be caused by the presence of H. pylori colonization of the antral mucosa and antral mucosal metaplasia of the proximal duodenum. In-vivo and in-vitro data support this concept; particularly with reference to the mechanisms of Helicobacter pylori induced aberrations in gastric and duodenal mucosal function.

Standard medical therapy for peptic ulcer disease includes anti-secretary medications as well as antibiotics designed to eradicate $H$. pylori colonization.

Complications of peptic ulcer disease are bleeding, perforation and gastric outlet obstruction. These complications can occur in patients with peptic ulcers of any etiology. Perforation occurs in about $5 \%$ to $10 \%$ of patients with active ulcer disease. ${ }^{1}$ Duodenal, antral and gastric body ulcers account for $60 \%, 20 \%$ and $20 \%$ of perforations, respectively, of peptic ulcers. Open and laparoscopic abdominal exploration is always indicated in gastro-duodenal perforation. Hemodynamic instability, signs of peritonitis and free extravagation of contrast material on upper gastrointestinal tract contrast studies make the decision for operation more urgent and imperative.

But, the advent of proton pump inhibitors and Helicobacter pylori eradication in the management of chronic peptic ulcer disease has reduced the operative treatment of this condition to its complications. Perforated duodenal ulcer remains a major life threatening complication of chronic peptic ulcer disease. The incidence of peptic ulcer disease in normal populations has declined over the past few years following a more streamlined pharmacological intervention. This can be attributed to the efficiency of histamine $\left(\mathrm{H}_{2}\right)$ blockers and proton pump inhibitors. ${ }^{2}$ Additionally, the diagnosis and eradication of Helicobacter pylori infection, now known to be a major factor in the pathogenesis of peptic ulcer disease, has almost eliminated the role of surgery in elective management of peptic ulcer disease. However, the incidence of perforated duodenal ulcers has either remained the same or has been increasing with the resultant increase in the incidence of emergency surgery. Although the use of potent $\mathrm{H}_{2}$ blockers and proton pump inhibitors has caused a marked decline in the incidence of peptic ulcer perforation, no such decline has been seen in the eradication of $H$. pylori infection.

Patients with perforated duodenal ulcers include those with acute ulcers, such as patients on non-steroidal antiinflammatory drugs (NSAIDs) and those with chronic ulcer disease who are refractory to or noncompliant with medical treatment. Another contributing factor to the increased incidence of perforation of duodenal ulcer is the decrease in elective anti-ulcer surgery. Patients presenting with an acute abdomen suggestive of a perforated duodenal ulcer are generally between 40 and 60 years of age although the number of patients over the age of 60 has been gradually increasing. Approximately $50 \%$ to $60 \%$ of these patients have a history of peptic ulcer disease, while a smaller number have a history of use of NSAIDs. ${ }^{2}$

Now, It's settled that $H$. pylori infection and NSAID use are two independent risk factors associated with perforated duodenal ulcers, and the lack of duodenitis in NSAID users as compared with those with $H$. pylori infection suggests a differing pathogenesis. The frequency of perforated peptic ulcer is decreasing among the overall population but it is becoming more frequent among old people. ${ }^{3}$ The higher mortality rate in the old population, justifies the search of prognostic factors specific for the elderly.

\section{METHODS}

\section{Study design}

Prospective non-randomized study.

\section{Study population}

All diagnosed cases of peptic ulcer perforation patients admitted through emergency or OPD in surgery ward in our Hospital.

\section{Inclusion criteria}

- Newly diagnosed cases of peptic ulcer disease perforation of stomach and duodenum.

- Anterior wall perforation either in pre-pyloric region or first part of duodenum.

- Patients of either sex.

- Patients of age group 11-70 years.

\section{Exclusion criteria}

- Perforation other than peptic ulcer disease of stomach and duodenum.

- Perforation other than pre-pyloric region or first part of duodenum.

- Perforation on the posterior wall or greater or lesser curvature of stomach or posterolateral wall of duodenum.

- Patients of heart disease who are on low dose aspirin.

- Patients not willing to participate in the study.

\section{Data collection}

- Patient's case record was evaluated to collect following data.

- Personal information: Name, age, sex, address, education and occupation, socioeconomic status, 
stress, alcohol, smoking and tobacco intake in any form.

- Past history of peptic ulcer disease, use of Nonsteroidal anti-inflammatory drugs for heart disease or osteoarthritis.

\section{Tests}

- Detail clinical history

- Patient's prescription

- Rapid urease test

- Upper GI endoscopy

\section{In our study we used rapid urease test}

Rapid urease test detects urease enzyme of Helicobacter pylori in gastric mucosal biopsy and gastric lavage.

Bedside kits are available for detection of Urease enzyme.

In this test colour change is observed from yellow to pink for $H$. pylori detection.

\section{Procedure}

- Gastric lavage or perforation site biopsy is taken as specimen.

- Peel back the label of kit and introduce the biopsy in exposed yellow media and one drop of sterile water then after covering the sticker as before.

- $\quad$ The colour changes from yellow to pink are called positive H. pylori.

- Observe the dot colour change from yellow to pink for 5 to 10 minutes.

- If colour changes from yellow to pink then result is positive.

- Endoscopy is routinely performed during follow up period to identify recurrence of Ulcer.

\section{RESULTS}

The present study is based on analysis of 50 cases of peptic ulcer perforation encountered in our institute between 2013-2015.

Table 1: Age distribution of patients.

\begin{tabular}{|lll|}
\hline AGE in years & No. of patients & Percentage(\%) \\
\hline $11-20$ & 04 & 08 \\
\hline $21-30$ & 06 & 12 \\
\hline $31-40$ & 09 & 18 \\
\hline $41-50$ & 10 & 20 \\
\hline$>50$ & 21 & 42 \\
\hline Total & 50 & 100 \\
\hline
\end{tabular}

In this study most patients with hollow viscus perforation were above the age of 50 years. The youngest patient in this study was 16 years with duodenal perforation and oldest was 75 years with duodenal ulcer perforation, so peptic perforation is common in above 50 year age (Table 1).

Table 2: Distribution of patients as per sex.

\begin{tabular}{|ll|l|}
\hline & Number of cases $(\mathbf{n}=\mathbf{5 0})$ & Percentage $(\boldsymbol{\%})$ \\
\hline Male & 42 & 84 \\
\hline Female & 08 & 16 \\
\hline Total & 50 & 100 \\
\hline
\end{tabular}

Hence frequency of peptic perforation is much greater in male compared to female. Perforation was found in 42 (84\%) cases out of 50 cases studied there were only eight cases of perforation in our study (Table 2).

Table 3: Presenting symptoms in patients with peptic perforation.

\begin{tabular}{|ll|l|}
\hline Symptoms & Number of cases & Percentage (\%) \\
\hline Pain & 50 & 100 \\
\hline Vomiting & 38 & 76 \\
\hline Constipation & 26 & 52 \\
\hline Fever & 24 & 48 \\
\hline Distension & 22 & 44 \\
\hline
\end{tabular}

Most common symptom in patients with perforation peritonitis was pain present in $100 \%$ patients, followed by vomiting $38(76 \%)$, constipation $26(52 \%)$ cases. Most commonly the patients came to hospital within 24 hours of onset of pain in abdomen (Table 3).

Table 4: Physical signs in patients with peptic perforation.

\begin{tabular}{|lll|}
\hline Physical examination & $\begin{array}{l}\text { Number } \\
(\mathbf{n = 5 0})\end{array}$ & $\begin{array}{l}\text { Percentage } \\
(\%)\end{array}$ \\
\hline Guarding and rigidity & 42 & 84 \\
\hline Distension & 40 & 80 \\
\hline rebound tenderness & 40 & 80 \\
\hline Absence bowel sounds & 35 & 70 \\
\hline Per rectal tenderness & 15 & 30 \\
\hline
\end{tabular}

On physical examination guarding and rigidity was present in $42(84 \%)$, followed by distension $40(80 \%)$, rebound tenderness $40(80 \%)$ cases, absence of bowel sounds $35(70 \%)$, raised per rectal tenderness $15(30 \%)$ cases (Table 4).

Table 5: Frequency of presence of free gas under diaphragm.

\begin{tabular}{|lll|}
\hline & Present & Absent \\
\hline Number & 40 & 10 \\
\hline Percent & 80 & 20 \\
\hline
\end{tabular}


In patients with suspected perforation peritonitis two types of X-rays were done i.e. X-ray erect abdomen and chest X-ray PA view. In majority of cases free gas under diaphragm seen i.e. 40 cases out of sample of 50 cases accounting for about $80 \%$ of cases (Table 5).

Table 6: complications in operated patients of peptic perforation.

\begin{tabular}{|lll|}
\hline Complications & Number & Percentage (\%) \\
\hline Number of complication & 32 & 64 \\
\hline Wound infection & 30 & 60 \\
\hline LRTI & 20 & 40 \\
\hline URTI & 12 & 24 \\
\hline Septicemic shock & 02 & 04 \\
\hline
\end{tabular}

Wound infection was found to be most important complication in patients presenting with peptic wound infection was found in $30(60 \%)$ cases, followed by lower respiratory tract infection $20(40 \%)$, septicemia due to peritonitis was found in $2(4 \%)$ cases, which was cause of mortality in that cases (Table 6).

Table 7: Ulcer recurrence in post operative period.

\begin{tabular}{|c|c|c|}
\hline & \multicolumn{2}{|c|}{$\begin{array}{l}\text { Number of patients receiving } \\
\text { triple drug therapy }\end{array}$} \\
\hline & $\begin{array}{l}\text { Suspected } \\
H . \text { pylori and } \\
\text { NSAID induced } \\
\text { peptic ulcer } \\
\text { perforation }\end{array}$ & $\begin{array}{l}\text { Suspected } \\
\text { non NSAID } \\
\text { non } H \text {. pylori } \\
\text { induced peptic } \\
\text { ulcer perforation }\end{array}$ \\
\hline Total & 48 & 2 \\
\hline Recurrence & 4 & 1 \\
\hline Non-recurrence & 44 & 1 \\
\hline
\end{tabular}

During post-operative period patients were followed up for 18 months and we found that, ulcer recurrence rate is $10 \%$ of total population. As p-value is significant, study proves that triple drug therapy is effective in preventing ulcer recurrence (Table 7).

Table 8: $\boldsymbol{H}$. Pylori detection.

\begin{tabular}{|l|ll|}
\hline & $\begin{array}{l}\text { Number } \\
\text { of cases } \\
\text { positive }\end{array}$ & $\begin{array}{l}\text { Number } \\
\text { of cases } \\
\text { negative }\end{array}$ \\
\hline Total number of cases $(\mathrm{n}=50)$ & 48 & 2 \\
\hline Percentage $(\%)$ & $96 \%$ & $4 \%$ \\
\hline
\end{tabular}

It shows that H. pylori is found in most of patients $96 \%$ patients of peptic perforation. Hence triple drug therapy is effective in preventing peptic ulcer recurrence (Table 8).

\section{DISCUSSION}

The mean age in this study was 41.78 years. Mean age of peptic perforation in Singh $\mathrm{R}$ et al study was 36.8 years, which comparable with our study results. ${ }^{4}$ Keneth $\mathrm{T}$ et al in their study of 172 cases of peptic perforation resulted mean age of perforation 68 years, and Buck DL, Anderson $\mathrm{V}$ et al found in their study of 2668 patient mean age of perforation to be 70.9 years. ${ }^{5,6}$

The ratio of male to female with peptic perforation was 5.25:1 in present study. Goyanka RG found sex ratio 4.2:1 which is comparable with our study. Dandpat MC found sex ratio of $8.4: 1 .{ }^{1,7}$ But most of western studies do not find any significant sex distribution for peptic perforation. ${ }^{5}$ Cases of perforation peritonitis are on rise in females due to smoking and alcohol drinking. ${ }^{8}$

Pain in abdomen, vomiting, distension and fever were the predominant symptoms in our study. Pain in abdomen was seen in all the cases. Jobta RS noted similar findings. ${ }^{4} \mathrm{He}$ also found that pain is present in all cases of perforation peritonitis and vomiting was present in $60 \%$, distension was present in $68 \%$.

In the present study majority of cases had guarding and rigidity $(84 \%)$ at presentation. Rebound tenderness $(80 \%)$ and absence of bowel sounds $(80 \%)$. In most of the studies conducted worldwide tenderness was present in all cases. JC Baid and TC Jain found guarding and rigidity in $85 \%$ of cases, distension in $56 \%$ cases. $^{9}$

Diagnosis is made clinically and confirmed by presence of pneumoperitoneum on radiograph. Presence of as under diaphragm has been a trademark of a hollow viscus perforation but absence of this does not exclude the presence of perforation. This sign is visualized in about $80 \%$ cases. Dandaput MC and colleagues noticed gas under diaphragm in $72.35 \%$ of cases. ${ }^{8}$ Willium $\mathrm{N}$ and Everson NW have reported $60-70 \%$ cases showing pneumoperitoneum in perforation peritonitis. ${ }^{10}$ Our study correlated well with above mentioned studies. Ultrasound of abdomen was not very sensitive and reliable investigation for perforation peritonitis.

The success of proton pump inhibitors and eradication of $H$. pylori has virtually eliminated need for elective surgery. Perforated peptic ulcer disease is common surgical emergency and major cause of death in elderly patients.

Perforated peptic ulcer is becoming common in older patients and associated with higher incidence of recent consumption non-steroidal anti-inflammatory drugs. ${ }^{1}$ There is significant association between $H$. pylori infection and concomitant use of NSAID and Steroids. All patients of perforation peritonitis were treated as surgical emergency. Preoperatively all patients had broad spectrum antibiotic coverage, nasogastric suction and management of fluid and electrolyte imbalance. Anemic 
patients required blood transfusion. Most common incision used for perforation peritonitis was Midline incision. Operative management consists of time honored practice of simple closure of perforation and omental patch closure. ${ }^{11}$ Post-operatively, in our study, parenteral antibiotics were continued for 7 days and after that oral antibiotics were given for 5 days. Usually ampicillin, metronidazole, ranitidine/omeprazole were given for 5-7 days.

All cases of peptic perforation underwent simple closure of perforation followed by omentopexy as described by Graham. ${ }^{11}$ In all cases of peritonitis thorough peritoneal lavage was given with $0.9 \%$ normal saline and drain were kept in pelvis and drain is usually removed on third to fifth post-operative day or when the drainage $<50 \mathrm{ml}$.

Nasogastric tube usually removed on second and third post-operative day and enteral feeding started on third and fourth day depending on bowel sounds. All patients were given chest physiotherapy and nebulization.

Post operatively patient received three drug regimen containing ampicillin, metronidazole, omeprazole for seven days. Patient is discharged after that and advised tablet ranitidine for 15 days, and to avoid alcohol drinking, smoking. They were kept on follow up for 12 18 months. It has been observed that ulcer recurrence rate is very low.

Following mentioned study used omeprazole, clarythromycin, amoxicillin as $H$. pylori eradication therapy for 6-12 weeks.

Post-operative ulcer recurrence in our study is $8 \%$ which is more compared to Sung JJ and Chung SC which showed $4.8 \%$ recurrence. $^{8}$ Fikry Youssef T, Sherief d et al showed $6.1 \%$ recurrence which is comparable with our study. ${ }^{12}$ Post operatively we used ampicillin, metronidazole, ranitidine (injectable form) for seven days. After that tablet ranitidine $150 \mathrm{mg}$ for 15 days is also effective. Results are comparable with above study. The regimen used by us is cost effective, with good patient compliance; low ulcer recurrence rate. Improved quality of life is partially responsible for low recurrence. Most common complication in our study was found to be wound infection (60\%) followed by LRTI (40\%). Sepsis was found in $4 \%$ cases. Post-operative mortality depends upon delay in treatment and associated comorbid condition. Mortality rate in our study was $4 \%$ compared with Dandapat MC et al reported $10.5 \%$. Jhobta R reported $10 \% .^{7,4}$

The mortality in our study was $6 \%$. Jobta $\mathrm{R}$ et al reported mortality of $10 \%{ }^{4}$ Worldwide literature showed that decrease in mortality of perforation peritonitis which ranges from $25 \%$ in 1940 as reported by Bakey D. ${ }^{13}$ Arveen S, Jagdish S et al (2009) in their study reported mortality of $8.5 \% .^{14}$

\section{CONCLUSION}

Perforation peritonitis is common in elderly population. Pain in abdomen and distension of abdomen are most common presenting feature. Early diagnosis by clinical assessment and presence of pneumoperitoneum is important followed by resuscitation and laparotomy with simple closure of perforation. Post-operative medical management by three drug therapy (ampicillin, metronidazole, ranitidine) followed by oral ranitidine for 15 days. Avoidance of non-steroidal anti-inflammatory drugs, smoking and drinking and life style modification is also important aspect. Patients are advised routine every six monthly follow up endoscopy for recurrence.

Funding: No funding sources

Conflict of interest: None declared

Ethical approval: The study was approved by the institutional ethics committee

\section{REFERENCES}

1. Goenka MK, Kochhar R, Ghosh P, Mehta SK. Changing pattern of peptic ulcer in India. J Clin Gastroenterol. 1991;13(5):575-9.

2. Niyaz A. 23 years of the discovery of Helicobacter pylori: Is the debate over? Ann Clin Microbiol Antimicrob. 2005;4:17.

3. Dunn BE, Cohen H, Blaser MJ. Helicobacter pylori. Clin Microbiol Rev.1997;10:720-41.

4. Jhobta RS, Attri AK, Kaushik R. Spectrum of perforation peritonitis in India-Review of 504 consecutive cases. World J Emergency Surg. 2006;1:26.

5. Thorsen K, Soreide JA, Kvaloy JT, Glomsaker T, Soreide K. Epidemiology of perforated peptic ulcer: Age and gender adjusted analysis of incidence and mortality. World J Gastroenterol. 2013;19(3):347-5.

6. Buck DL, Vester AM, Moller MH. Surgical delay is a critical determinant of survival in perforated peptic ulcer. Br J Surg. 2013;100(8):1045-9.

7. Dandaput MC. Gastrointestinal perforation: Review of 340 cases. Indian J Surg. 1991;53(5):189-19.

8. Ng EK, Lam YH, Sung JJ, Yung MY, To KF, Chan AC, et al. Eradication of Helicobacter pylori prevents recurrence of ulcer after simple closure of duodenal ulcer perforation: randomized controlled trial. Ann Surg. 2000;231(2):153-8.

9. Baid JC, Jain TC. Intestinal perforation. Indian J Surg. 1988;50:335-7.

10. Willium N, Everson NW. Radiological conformation of intra peritoneal free gas, Ann Royal College Surg. 1997;79(1):8-12.

11. Richter JE, Folk GW, Vaezi MF. Helicobacter pylori and gastroesophageal reflux disease: the bug may not be all bad. Am J Gastroenterol. 1999;93:1800-2.

12. El-Nakeeb A, Fikry A, Abd TM, Fouda el, Awady ES, Youssef T, Sherief D, Farid M Effect of Helicobacter pylori eradication on ulcer recurrence 
after simple closure of perforated duodenal ulcer. J Gastroenterol Hepatol. 2007;22(3):345-8.

13. Bakey D, Jordan GL. Surgical management acute gastrointestinal perfoaration: Am J Surg. 1961;101:317-23.
14. Arveen S, Jagdish S, Kadambari D. Perforated peptic ulcer in South India: an institutional perspective. World J Surg. 2009;33(8):1600-4.

Cite this article as: Deshmukh SB, Kondawar KU, Gireboinwd S, Chawada MJ. Study of the effect of post-operative medical management on peptic ulcer in patients of perforated peptic ulcer disease. Int Surg J 2016;3:1267-72. 